\title{
Missões jesuíticas dos Sete Povos e o Tratado de Madri (1750): protagonismo, resistência e autodeterminação dos índios na luta pela terra
}

\author{
Jesuit Missions of the Seven People and the Treaty \\ of Madrid (1750): protagonism, resistance and \\ self-determinations of indians in the struggle for the land
}

\author{
Mateus Brunetto Cari ${ }^{1}$ \\ Paula Faustino Sampaio²
}

DOI: 10.20435/tellus.v0i0.534

\begin{abstract}
Resumo: Este estudo aborda o processo de resistência dos guarani das missões dos Sete Povos entre os anos de 1750 e 1756 contra o Tratado de Madri (1750), destacando como a resistência indígena se configura enquanto um processo de reconhecimento de direitos e de diferenças sociais, econômicas e culturais em relação ao modelo colonial. Desse modo, a resistência dos guarani-missioneiros ganha contornos de autodeterminação de sujeitos subalternizados no aporte teórico decolonial. Nesse sentido, este artigo aborda, brevemente, o processo de transformação cultural e constituição da identidade étnica guarani-missioneiro, e como a luta contra as prerrogativas do Tratado de Madri foi uma busca por manutenção da unidade étnica constituída no cosmos missioneiro. A partir disso, aborda-se a consciência dos guarani-missioneiros de sua importância nos meandros geopolíticos dos séculos XVII e XVIII na região platina e, de igual modo, problematiza-se a situação de negociações entre os indígenas e outros atores que compunham o cenário geopolítico da região, afinal, quando obrigados a saírem de suas terras, os guarani-missioneiros resistiram, advertindo a elite colonial dos seus feitos em prol da Espanha. O objetivo central é, pois, apresentar o protagonismo indígena no processo de luta pela terra e por seus direitos, através de uma perspectiva epistemológica que transcenda as velhas análises eurocêntricas e etnocêntricas sobre o passado missioneiro: em termos historiográficos, utilizaremos estudos comprometidos com um olhar crítico das fontes, tais como Meliá (1978), Kern (1982), Neumann (2005) e Langer (2005).
\end{abstract}

1 Universidade Federal da Grande Dourados (UFGD), Dourados, Mato Grosso do Sul, Brasil.

2 Universidade Federal do Mato Grosso (UFMT), Rondonópolis, Mato Grosso, Brasil. 
Palavras-chave: resistência; autodeterminação; Guarani-missioneiros; colonialidade de gênero.

\begin{abstract}
This study approaches the process of resistance of the guarani from missions between 1750 and 1756 against the Treaty of Madrid (1750), highlighting how the indigenous resistance is a process of recognition of rights and of socioeconomic and sociocultural differences in relation to the colonial model. Thereby, the resistance of guarani-missionaries obtains characteristics of self-determination of subalternized subjects in decolonial theoretical contribution. In this sense, this article approaches, briefly, the process of cultural transformation and the constitution of ethnical identity guarani-missionaries, and how the fight against the prerogatives of treaty is a pursuit to keep the ethnical unit constituted in the missionary cosmos. From this, it is approached the consciousness of the guarani-missionaries about their importance to the geopolitical scenario in XVII and XVIII centuries in platinum region and, also, it is problematized the negotiations between the indigenous and the other actors that composed that scenario, because, when they were forced to leave their land, the guarani-missionaries resisted, warning the king about their perform in benefit of Spain. The aim will be, therefore, to present indigenous protagonism in the fight process for their land and their rights, through a notion that transcends the old eurocentrics and ethnocentrics analysis about the missionary past: in historiographical terms, we will use studies compromised with critical approaches of the documents, such as Meliá (1978), Kern (1982), Neumann (2005) and Langer (2005).
\end{abstract}

Keywords: resistance; self-determination; Guarani-missionaries; coloniality of gender.

\title{
1 INTRODUÇÃO
}

A experiência missioneira na província jesuítica do Paraguai, entre início do século XVII e segunda metade do século XVIII, rendeu importantes debates e grandes controvérsias historiográficas ao longo do tempo. Diferentes correntes historiográficas versaram sobre o período em questão. Por um lado, uma historiografia lusitana buscava construir um discurso de unidade nacional nas terras que compunham os Sete Povos, negando a importância do projeto missioneiro e os guarani nos diferentes processos de formação do território nacional e, de igual modo, da identidade nacional. Por outro lado, uma corrente historiográfica jesuítica vangloriava o trabalho dos padres jesuítas junto aos guarani das missões e, no mesmo movimento, buscava eximir de culpa os padres que foram acusados de incitarem os guarani a resistirem às prerrogativas do Tratado de Madri (1750 
in SOUZA, 1939) ${ }^{3}$. Ambas as correntes davam pouca importância aos guarani das missões, os índios não passavam de seres infantis, incapazes de agirem segundo seus próprios interesses. Na perspectiva antimissioneira, destacamos Vellinho (1970), Goulart (1978), além de Porto (1954), o qual acabou atendendo aos anseios tanto de lusitanistas, quanto de jesuítas. No que se refere aos que exaltam a experiência reducional, destacam-se Bruxel (1978), Lugon (1976), Teschauer (1921), Jaeger (1940) e Bernardi (1957).

$\mathrm{Na}$ esteira disso, surge uma terceira corrente historiográfica que ampliou o leque de análise e problematizações acerca das missões jesuíticas. Trata-se de uma historiografia responsável por se afastar do etnocentrismo e do eurocentrismo, que prendiam as potencialidades de análises históricas do período. Essa historiografia permitiu uma visão crítica das fontes disponíveis, apontando o protagonismo indígena, por um lado, e desmascarando o ufanismo sobre a temática, por outro. A partir das abordagens dessa corrente, as pesquisas sobre o passado missioneiro deram um salto, tanto em quantidade, quanto, principalmente, em qualidade de análises. Destacam-se, nessa corrente, os escritos de Meliá (1997; 1978) Meliá e Nagel (1995), Kern (1982; 1985), Quevedo (1996; 2000), Flores (1996) e, tratando especificamente da guerra guaranítica, Golin (1998; 2014); sobre representações de mulheres guarani nas reduções, Fleck (2006).

O presente artigo tem a intenção de se inserir nesse terceiro debate, apontando o protagonismo e resistência dos(as) guarani mediante as prerrogativas do Tratado de Madri de $1750^{4}$ (in SOUZA, 1939). Desse modo, o objeto de estudo aqui proposto refere-se ao processo de resistência e autodeterminação de sujeitos subalternizados nas missões dos Sete Povos na Guerra Guaranítica (1750-1756). Quando nos referimos a sujeitos subalternizados, compreende-se que se trata da-

3 O Tratado de Madri, basicamente, passaria as terras dos Sete Povos para Portugal, que, em troca, passaria a colônia de Sacramento para a Espanha. Nessa permuta, as missões dos Sete Povos deveriam ser abandonadas, e os guarani teriam que migrar para a outra margem do rio, onde se encontravam os outros vinte e três povos das missões.

4 Em linhas gerais, o Tratado de Madri foi assinado com intuito de resolver os impasses fronteiriços entre Portugal e Espanha na região platina. Essa região se notabilizou por constantes conflitos geopolíticos, os quais ocorriam, principalmente, pela imprecisão do Tratado de Tordesilhas em definir as possessões de cada império. O Tratado de Madri passaria a Colônia de Sacramento nas margens do rio da Prata para Espanha, que, em contrapartida, entregaria os Sete Povos das Missões para Portugal. Ademais, o elemento que figuraria a posse da terra na região era sua ocupação de fato, o chamado uti possedetis. 
queles que vivem à margem do paradigma hegemônico, que são constantemente postos em condição de inferioridade (MASO; SÉLIS, 2014).

Tendo em vista o objeto proposto, as perguntas a que se quer responder são: como se processou a resistência dos guarani-missioneiros? A luta dos guarani-missioneiros por seus territórios refletem consciências mais profundas daqueles sujeitos? A partir da lente decolonial, seguindo as propostas de Quijano, Mignolo, Dussel, Torres, Lander, Grosfoguel, Lugones, Anzaldua, a resistência guarani pode ser entendida através da noção de descolonialidade?

A principal hipótese deste trabalho indica que a resistência refletia consciências mais profundas ${ }^{5}$ dos guarani-missioneiros: eles reconheciam seus direitos sobre aquele território, reconheciam as diferenças socioculturais e socioeconômicas em relação ao modelo colonial e, reconhecendo essas diferenças, sabiam que perder aquele território implicaria o comprometimento das práticas e no modo de vida do grupo. Assim sendo, entendo que o reconhecimento desses fatores traz uma marca característica para a resistência: a da autodeterminação de sujeitos subalternizados.

A partir do reconhecimento desses fatores, pode ser possível compreender um processo de transcendência de colonialidades, isto é, de descolonialidade, pois a consciência dos(as) guarani-missioneiros(as) da importância de manter seu modo coletivo de produção, sem aderir ao mercantilismo colonial, mais do que um processo de sustentação de valores de identidade étnica, é um processo que, com a lente decolonial, reflete uma superação de um modelo eurocêntrico. A escolha por um modelo econômico e produtivo calcado em suas práticas tribais, que supera a oposição inclusive dos jesuítas, indica o pensar e agir por si mesmo; trata-se de agir e pensar por si próprios (autodeterminados) descolados do colonizador, do opressor.

Além disso, a descolonialidade reside no fato de que o guarani-missioneiro identificava a si mesmo como um ser diferente do europeu, que, ao ver o jesuíta

5 Quando nos referimos à noção de consciências mais profundas, entende-se que os guarani compreendiam que possuíam direitos sobre as terras e, de igual modo, sabiam que sua organização econômica, social e cultural dentro das reduções era diferente da sociedade circundante, ainda que estivesse sob a égide do colonialismo e funcionasse em prol do projeto colonial. Observando essa diferença e compreendendo a totalidade do sistema colonial, os índios das missões entendiam que o modelo reducional era a condição mais favorável para sobrevivência dos grupos indígenas. Ou seja, trata-se de estratégias de sobrevivência dos guarani-missioneiros. 
cristão, o colono espanhol e o bandeirante português, colocava-se enquanto um nativo com construções políticas, sociais e culturais já estabelecidas ${ }^{6}$.

O aporte teórico para levar adiante essas propostas é o decolonial. Seguem, brevemente, uma apresentação dos estudos decoloniais e algumas teorizações que contemplem questões da colonialidade, autodeterminação, descolonialidade e colonialidade de gênero.

Os estudos decoloniais surgiram na década de 1990 com o Grupo Modernidade/Colonialidade (M/C). Formado por intelectuais da América Latina, o objetivo do $\mathrm{M} / \mathrm{C}$ foi a radicalização das proposições dos estudos pós-coloniais. Os estudos pós-coloniais propuseram a superação da colonização, do colonialismo e da colonialidade. Indo além, os estudos decoloniais defenderam o "giro decolonial", ou seja, a resistência teórica, epistemológica, política e prática à modernidade e à colonialidade desde a América Latina (BALLESTRIN, 2013).

Mignolo (2003) não observa os conceitos de colonialidade e modernidade separadamente, os quais são, pelo contrário, processos que ocorrem simultaneamente. Por isso afirma-se que "a conexão do Mediterrâneo com o Atlântico através de um novo circuito comercial, no século XVI, lança as fundações tanto da modernidade como da colonialidade" (MIGNOLO, 2003, p. 83). Assim, "a coexistência histórica da expulsão dos judeus e mouros da Espanha e a 'descoberta' da América, era, ao mesmo tempo, um marco tanto do colonialismo moderno quando das modernidades coloniais - ou seja, da modernidade/colonialidade" (MIGNOLO, 2003, p. 80). Foi o momento da emergência, portanto, de um novo sistema mundial, bem como da modernidade/colonialidade, refletidos na experiência espanhola descrita acima. Essa co-constituição de modernidade/colonialidade é perpassada pelos conceitos de colonialidade do saber, colonialidade do poder e do ser?

6 "Eles também tinham seus especialistas da magia, na explicação dos fenômenos naturais, das causas e curas das doenças, da individuação da propriedade dos elementos da natureza; os intérpretes dos sonhos e dos mistérios, os guardiões da memória. [...] Entre eles havia o conflito pela representação do sagrado, da medicina e da memória" (GOLIN, 2010, p. 29).

7 “[...] la colonialidad del poder se refiere a la interrelación entre formas modernas de explotación y dominación, y la colonialidad del saber tiene que ver con el rol de la epistemología y las tareas generales de la producción del conocimiento en la reproducción de regímenes de pensamiento coloniales, la colonialidad del ser se refiere, entonces, a la experiencia vivida de la colonización y su impacto en el lenguaje" (TORRES-MALDONADO, 2007, p. 130). 
O conceito de colonialidade do poder foi desenvolvido, em 1989, por Anibal Quijano. Esse conceito aponta que, mesmo com o fim do colonialismo, a colonialidade permaneceu arraigada nos âmbitos da política e da economia (BALLESTRIN, 2013).

Nesse sentido, Quijano (2005) aponta que, na descoberta da América, criaram-se novas identidades baseadas na noção de raça, que se ligaram às diferentes funções que os indivíduos assumiriam na estrutura global do trabalho, ou seja, negros e índios se limitariam a ocupar lugares renegados na divisão internacional do trabalho, enquanto os de pele branca poderiam assumir lugares de maior prestígio. Trata-se da divisão racial do trabalho que marca a modernidade/ colonialidade. Desse modo, descreve-se que:

A distribuição racista do trabalho no interior do capitalismo colonial/moderno manteve-se ao longo de todo o período colonial. No curso da expansão mundial da dominação colonial por parte da mesma raça dominante - os brancos (ou do século XVIII em diante, os europeus) - foi imposto o mesmo critério de classificação social a toda a população mundial em escala global. [...] Essa distribuição racista de novas identidades sociais foi combinada, tal como havia sido tão exitosamente logrado na América, com uma distribuição racista do trabalho e das formas de exploração do capitalismo colonial. [...] [De modo que] cada forma de controle do trabalho esteve articulada com uma raça particular. [...] [Assim] Uma nova tecnologia de dominação/exploração, neste caso raça/trabalho, articulou-se de maneira que aparecesse como naturalmente associada, o que, até o momento, tem sido excepcionalmente bem-sucedido. (QUIJANO, 2005, p. 229-30).

A colonialidade do poder pode ser entendida, portanto, como a perpetuação da divisão racial nas esferas político, econômica e também social do sistema colonial/moderno, mesmo com o fim da colonização. Em suma, a colonialidade do poder, com a noção de divisão estrutural de raça, marca "o princípio organizador que estrutura todas as múltiplas hierarquias do sistema-mundo" (GROSFOGUEL, 2008, p. 123, apud BALLESTRIN, 2013, p. 101).

Tem-se também, nesse contexto, a colonialidade do ser, que surge enquanto conceito para responder sobre os efeitos produzidos pela colonialidade na vivência e na mente dos subalternizados. A colonialidade do ser, desse modo, está fundamentada em uma diferença ontológica, enquanto a colonialidade do saber é fundamentada na diferença epistemológica, as quais se relacionam na coloniali- 
dade do poder (dominação, exploração e controle) (TORRES-MALDONADO, 2007). Sendo assim, "[...] la diferencia [...] ontológica colonial se refiere a la colonialidad del ser en una forma similar a como la diferencia epistémica colonial se relaciona con la colonialidad del saber" (TORRES-MALDONADO, 2007, p. 147).

Nesse ínterim, também surgiram as críticas das intelectuais feministas à relação entre pós-colonialismo e feminismo e ao pensamento sobre sexo/gênero de Anibal Quijano, intelectual dos estudos decoloniais. Essas críticas impulsionaram, nos estudos pós-coloniais, os debates sobre poder e subalternidade das mulheres (SPIVAK, 2010) e, nos estudos decoloniais, as discussões sobre colonialidade de gênero (LUGONES, 2015). Em ambas as perspectivas epistemológicas, ficou evidente a centralidade das questões de gênero no projeto colonial; e, em particular, nos estudos decoloniais, a urgência da descolonização e da despatriarcalização do pensamento (MOHANTY, 2008).

Em especial, a crítica atual ao universalismo feminista realizada por mulheres de cor e do terceito mundo está centrada na reivindicação de que a intersecção entre raça, classe, sexualidade e gênero vai além das categorias homogêneas, atomizadas e separáveis, como são as categorias da modernidade que organizam o mundo ontologicamente (LUGONES, 2014). A intersecção das categorias mostra a ausência, e não a presença, portanto "Ver mulheres não brancas é ir além da lógica 'categorial'” (LUGONES, 2014, p. 935). Esta autora propõe o sistema moderno colonial de gênero como uma lente com a qual se pode aprofundar a teorização da lógica opressiva da modernidade colonial, bem como criticar o uso de dicotomias hierárquicas e da lógica categorial de sexo e de gênero no pensamento decolonial.

Nesse sentido, Lugones $(2015 ; 2014)$ investiga a imposição de categorias aos sujeitos colonizados e mostra a colonialidade de gênero como "o processo de redução ativo das pessoas, a desumanização que as torna aptas para a classificação, o processo de sujeitificação e a investida de tornar o/a colonizado/a menos que seres humanos." (LUGONES, 2014, p. 939). A colonialidade de gênero é uma marca da modernidade colonial que, na América e Caribe, foi imposta primeiro como a distinção entre humano e não humano, acompanhada por outras distinções hierárquicas dicotômicas, a exemplo das distinções de sexo e gênero. Lugones (2014, p. 940) sugere, então, um deslocamento metodológico visando 
a "entender a resistência à colonialidade do gênero a partir da perspectiva da diferença colonial". Trata-se de um convite a um feminismo descolonial.

Em termos teóricos e metodológicos, a opção pelos estudos decoloniais coaduna com a operacionalização da etno-história. Em um estudo sobre o lugar que ocupa a etno-história e como operacionalizá-la, Rojas (2008) aponta que ela se constitui em uma busca comum para reconstruir e interpretar o processo como um todo da história e cultura na América, desde a colonização até o presente. Nesse sentido, tendo em vista seu caráter interdisciplinar, a etno-história abre espaço para práticas de pesquisa que não teriam abertura em outras disciplinas. São métodos e teorias que auxiliam no avanço dos conhecimentos para se pensar novos problemas e análises da documentação.

Essa constatação diz muito sobre a etno-história enquanto método, principalmente para a pesquisa aqui apresentada, pois ela abre possibilidades para se propor novas perguntas ao passado, ampliando a possibilidade de análises. Nesse sentido "[...] a etno-história, como método interdisciplinar, é o melhor caminho para se compreender os povos de culturas não ocidentais a partir de uma perspectiva histórica" (CAVALCANTE, 2011, p. 359).

Pensando no que é mais caro aqui, a fonte escrita, a etno-história consiste em uma crítica documental. Citando Meliá (1997), Cavalcante (2011) aponta que o método etno-histórico deve desideologizar as fontes, isto é, apresentar seu lugar de produção, analisando os discursos nelas contidas acerca dos povos indígenas.

No que se refere à documentação, neste artigo utilizaremos as cartas do guarani-missioneiros dos Sete Povos sublevados em resposta ao governador de Buenos Aires, José Andonanhegui. Diante da negativa dos indígenas dos Sete Povos à mudança, exceto o povo de São Borja, que aceitara as ordens do Tratado de Madri, Andonanhegui enviou uma carta aos povoados fazendo fortes ameaças de guerra aos indígenas caso permanecessem intransigentes em não deixarem as terras. Essa fonte é primordial para uma análise que busque se inserir em uma abordagem epistemológica descolonizada, pois contém elementos para refletir sobre as ações emancipadas dos(as) indígenas, que tiveram na escrita um mecanismo de emancipação da tutela jesuíta e, por conseguinte, puderam levar a cabo seus interesses naquele contexto. Essas cartas foram escritas originalmente em 
guarani e, depois, traduzidas ao espanhol. As que dispomos para este trabalho foram traduzidas para o português por Rabuske (1978).

Também constitui fonte histórica nesta reflexão a produção historiográfica sobre mulheres guarani nas reduções jesuíticas-guaranis da Província do Paraguai, século XVII. Trata-se de estudos preocupados com as representações sobre as mulheres guarani nos escritos jesuíticos, bem como em discutir o protagonismo de mulheres na resistência cotidiana à normatização da sexualidade imposta nas reduções pelos padres inacianos. Em grande medida, López de Mariscal (1997), Fleck (2006), Martins (2000) e Mendes (2013) estudam as Ânuas - relatórios anuais direcionados ao Padre Geral da Companhia de Jesus pelos Padres Provinciais, os escritos dos cronistas da Companhia de Jesus e de demais cronista da colonização da América. Esses autores mostram o lugar secundário das informações sobre as mulheres indígenas nessa documentação, discutindo as possíveis razões de tal minoração do sujeito mulher das narrativas escritas das reduções jesuíticas-guaranis. Nesse diapasão, Fleck (2006) aponta a diminuta discussão sobre gênero e etnias indígenas na historiografia e elenca os estudos existentes:

Apesar de não existir uma discussão extensa relacionando gênero e etnias indígenas, autores como Tzvetan Todorov, Blanca López de Mariscal e Ronald Raminelli abordaram as primeiras impressões acerca das mulheres indígenas na América hispânica e portuguesa, tendo como fontes relatos de conquistadores, viajantes e missionários. Dentre as significativas produções sobre a mulher indígena da região andina, destacamos o trabalho de Ana Maria Lorandi e Mercedes Del Rio e, sobre a mulher Guarani, os estudos de Bartomeu Melià, Ana Díaz de Guerra e Beatriz dos Santos Landa, os quais referem não somente os papéis assumidos pelas mulheres na sociedade indígena, mas também as alterações dos mesmos em face dos projetos de colonização e de evangelização. (FLECK, 2006, p. 617).

Analisar essa documentação, usual nos estudos históricos sobre as missões jesuíticas-guaranis, sob uma mirada decolonial feminista com a metodologia da etno-história, é um desafio e um convite a, no campo histórico, interseccionar perspectivas, metodologias e categorias tendo como horizonte a descolonização, a despatriarcalização e a desideolização da escrita histórica. 


\section{O(A) GUARANI REDUZIDO(A): TRANSFORMAÇÃO E CONSTRUÇÃO DA IDENTIDADE ÉTNICA GUARANI-MISSIONEIRA}

Como parte integrante deste objeto, deve-se compreender que a cultura dos guarani não foi "aculturada", mas sim passou por um processo de transformação, forjou-se um novo modo de vida entre os guarani das missões. Assim, a identidade étnica se constrói no contato interétnico com outros grupos. Nesse sentido, Langer (2005) observa que os contatos interétnicos entre os guarani das missões e outras parcelas da sociedade colonial levavam ao surgimento de uma nova identidade étnica: a dos guarani-missioneiros

Ou seja, os guarani-missioneiros não aceitaram passivamente a imposição unilateral de um novo modo de vida, pois, de acordo com Golin (2014), havia tensões internas entre os cabildos e os jesuítas, formando-se um sistema híbrido espanhol-jesuítico e jesuítico-guarani. Kern (1982) também demonstra que a experiência missioneira foi marcada por adaptações e readaptações da fé católica e do sistema político espanhol à tradição guarani.

A noção de transformação cultural e, por conseguinte, de estratégias e de readaptações para sobrevivência da unidade de grupo é ponto inicial desta proposta, pois essa noção precede a possibilidade de se analisar resistência e autodeterminação. Isto é, uma perspectiva de assimilação completa comprometeria a análise sobre resistência e autodeterminação, pois a resistência, a autodeterminação, a emancipação e a luta por libertação são precedidas pelo reconhecimento de direitos, por autoafirmação enquanto grupo, que observando o outro, coloca-se enquanto diferente.

Assim sendo, há diferenças significativas entre os valores ocidentais e os valores dos guarani-missioneiros. Diferenças que se constituíram na alteridade, diferenças que, na incompatibilidade com o mundo colonial, fizeram com que os guarani-missioneiros escolhessem a via da guerra e da resistência para conservarem o seu modus vivendi construído nas reduções.

Desse modo, a primeira consideração a ser feita é que a cultura não se configura como uma unidade homogênea compartilhada, pois a cultura de um povo pode ser perpetuada fora do que é tradicional em situações de contato, de modo que, por vezes, a criatividade individual aparecerá como elemento perpetuador, representando a coletividade (COHN, 2001). 
Assim sendo, pode-se entender que a perda de características e traços não acaba com determinada cultura, pois "[...] a fronteira etnica que defini o grupo, não as características culturais que ela inclui" (BARTH, 1969, p. 15, tradução nossa). Nesse sentido, em contato com outras culturas, determinado grupo étnico manterá sua unidade na medida em que conservar os traços de diferenciação de comportamento, ou a própria diferenciação dos elementos que compõem a cultura. Ou seja, mais do que os traços culturais, o que importa é a diferença que se constrói na alteridade, de modo que uma cultura não deixa de existir porque perdeu integridade, afinal o que a constitui é a sua diferença com outras.

A pergunta que surge é: como um grupo mantém as características de diferenciação em contextos de contatos tão intensos? Essas características de diferenciação se sobressaem no contato, pois a identidade étnica está inserida numa noção de identidade contrastiva, de modo que a autoafirmação de um grupo ou de uma pessoa ocorre a partir da diferenciação na relação com o outro, que se afirma negando a outra identidade. Ou seja, a identidade étnica se constrói no contraste com o outro, na alteridade, através de uma "autoapreensão de si em situação". Assim, o contexto de contato interétnico é o que constitui a identidade étnica, principalmente a partir da friç̧ão interétnica ${ }^{8}$ (OLIVEIRA, 2003).

Por exemplo, o caráter da guerra tribal guarani foi modificado em suas motivações, ritos e objetivos, todavia os relatos das missões mostram que a prática bélica estava no cotidiano da redução com exercícios diários, bem como peças teatrais e para solenizar festividades, de modo que "[...] os valores bélicos estavam entranhados no corpo social das reduções e que os estímulos ao aprimoramento das técnicas a ao incitamento dos impulsos guerreiros acorriam de múltiplas maneiras" (LANGER, 2005, p. 75-6). É interessante notar que, a partir do contato e da evangelização, a guerra teve sua forma modificada, entretanto os elementos da guerra que delineavam e diferenciavam a identidade étnica guarani sobreviveram à passagem da sociedade tribal para a situação reducional.

Desse modo, a noção de transformação cultural pode ser entendida a partir do estudo das maneiras que os grupos lidam, adaptam, readaptam ou interagem

\footnotetext{
8 "Essa noção supõe [...] que o sistema interétnico constituído por mecanismos de articulação das unidades étnicas em contato se apresenta em permanente equilíbrio instável e que o fator dinâmico do sistema está no próprio conflito, seja manifesto ou seja latente" (OLIVEIRA, 1976, p. 58).
} 
com diferentes formas de contato. Destarte, "as sociedades indígenas atuam sempre na reconstituição de uma identidade diferenciada" (COHN, 2001, p. 37), e, por isso, suas culturas, apesar de terem suas formas de reprodução e transmissão transformadas, mantêm suas características de diferenciação presentes.

A transformação cultural nas missões não se processava em uma via de mão única, pois a cultura dos guarani também insidia sobre as práticas cristãs e as transformava, de modo que se constituiu "[...] um cristianismo híbrido onde conviviam elementos da cultura europeia com a do ameríndio, não sem conflitos" (OLIVEIRA, O, 2014, p. 94).

Uma grande transformação na cultura guarani foi a substituição do xamã enquanto líder espiritual pelo jesuíta e, por conseguinte, a introdução do cristianismo como religião oficial. Contudo, esse cristianismo possuía traços muito particulares da espiritualidade tribal dos guarani: uma passagem de Montoya (1985, p. 54) descreve que, durante o ritual católico do sepultamento nas reduções juntamente com outros índios,

[...] uma velhinha, munida duma peneira assaz curiosa e pequena, e, da mesma forma velada ou fingida, agitava a tal peneira pela sepultura, como se tirasse qualquer coisa. À vista disso diziam os índios que com isso tiravam a alma do defunto, para ela não padecer enterrada com o seu corpo. (MONTOYA, 1985, p. 54).

A despeito de um sepultamento cristão, os traços de diferenciação estavam presentes através da senhora que praticava um ritual tradicional da tribo. Isso quer dizer que a cultura foi transformada, mas as fronteiras de diferenciação do grupo perduraram.

A principal estratégia de evangelização empregada pelos jesuítas foi o domínio da língua guarani. Neumann (2005) aborda a introdução da palavra escrita junto aos guarani, observando-a como uma grande transformação cultural, visto que a escrita não fazia parte da lógica indígena. Contudo os guarani se adaptaram a essa nova forma da palavra e se apropriaram da escrita para seus próprios objetivos, fazendo dela um mecanismo de emancipação da tutela jesuíta e, por conseguinte, de autogoverno, na medida em que estabeleciam comunicação direta com os atores que compunham o mundo colonial, que é o caso das cartas em oposição ao tratado de 1750. 


\section{A RESISTÊNCIA DOS GUARANI-MISSIONEIROS: APONTAMENTOS GEOPOLÍTICOS, NEGOCIAÇÕES E LIGAÇÃO COM A TERRA}

As reduções dos Sete Povos tinham importância geopolítica singular: por se situarem na região sul do território espanhol, eram a linha de frente contra os portugueses que, desde muito, haviam "rompido" a linha de Tordesilhas e fundado a Colônia de Sacramento às margens do Prata. De acordo com Golin (2014), as missões formavam barreira geopolítica contra o avanço lusitano.

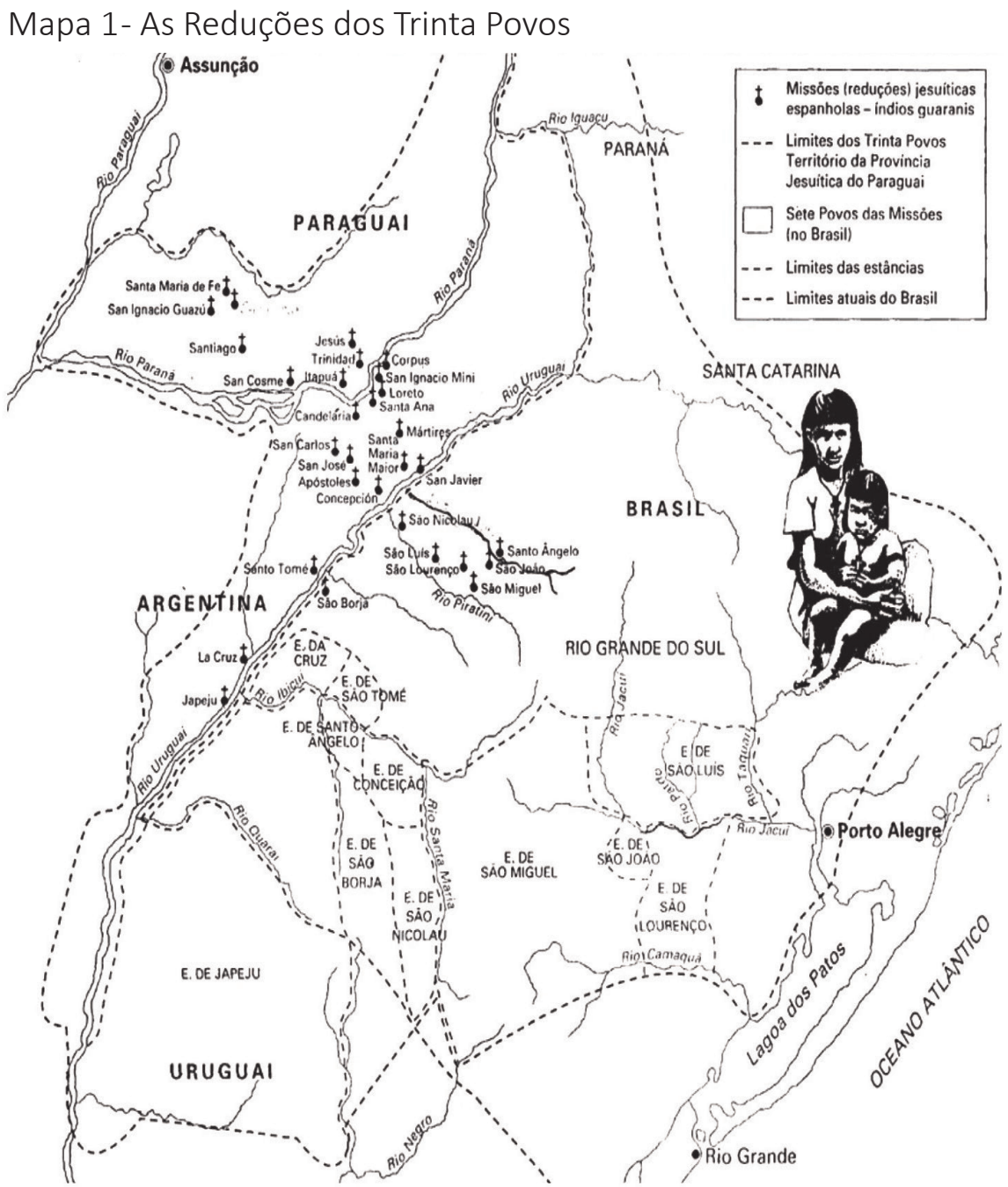

Fonte: Quevedo (1996). 
Além disso, os guarani-missioneiros defenderam, inúmeras vezes, o território espanhol dos avanços dos portugueses. Através das cartas dos guarani-missioneiros, pode-se notar a consciência que tinham de sua importância nos meandros geopolíticos da época ${ }^{9}$. Isso se evidencia quando lembravam as suas diversas ações na defesa do território espanhol contra os ataques portugueses: os índios de São João, ao falarem que nunca fizeram mal ao rei espanhol, apontavam que "Pelo contrário, fomos até duas vezes à Colônia (de Sacramento), para de lá expulsarmos os portugueses" (CARTA DO POVO DE SÃO JOÃO, [1753] in RABUSKE, 1978, p. 71).

Nesse sentido, fazia o seguinte questionamento o povo de São Lourenço: "Não sabes acaso que os portugueses são inimigos do rei da Espanha? Sabemolo (até nós) muito bem." E continuam: "Por ventura tu, senhor governador, te constituíste, em nome do rei da Espanha, cúmplice ('ajudador') dos portugueses?" (CARTA DO POVO DE SÃO LOURENÇO, [1753] in RABUSKE, 1978, p. 74) ${ }^{10}$. Portanto, os guarani-missioneiros sabiam que Portugal era inimigo espanhol e, de igual modo, ao resgatarem o que já haviam feito contra os portugueses em nome da Espanha, demonstravam reconhecer sua importância naquele contexto de tensões políticas.

A Coroa espanhola usou os guarani-missioneiros nos seus intentos geopolíticos. Ao assinar o Tratado de Madri, Espanha e Portugal satisfaziam seus interesses. Bastava tão somente proceder com o transladado dos guarani-missioneiros para os outros povoados. Não esperavam, entretanto, que os índios tivessem suas próprias demandas, seus próprios objetivos e interesses, afinal, pensavam os ibéricos, eram infantis enquanto civilização.

Contudo os guarani-missioneiros, ao resistirem às prerrogativas do tratado, assinalavam que tinham interesses próprios e que não sairiam de suas terras

9 A importância dos guarani-missioneiros na defesa e manutenção do território espanhol é amplamente debatida pela historiografia. A criação do exército guarani no século XVII foi uma estratégia para barrar o avanço lusitano nas fronteiras platinas, mal definidas pela subjetividade do Tratado de Tordesilhas. Em anos de reduções, os guarani-missioneiros defenderam as cidades de Buenos Aires, Santa Fé, Corrientes e, principalmente, Assunção das investidas portuguesas e de coletivos indígenas não reduzidos. Para mais informações sobre o exército guarani ver Kern (1982) e Neumann (1996).

${ }^{10}$ A carta do povo de São Lourenço não estava datada, contudo, tendo em vista que as demais cartas são de 1753 e foram uma reação coletiva às ameaças do governador Andonanhegui, presume-se também ser de 1753. 
sem lutarem. Nesse sentido, pode-se questionar o que era negociado naquela realidade: os guarani-missioneiros se tornaram vassalos da Espanha, aderiram ao cristianismo, mas tudo isso funcionava em um movimento de trocas. Ao serem vassalos, cristãos e guerreiros do rei espanhol, preservavam o grupo, livrando-se do jugo dos bandeirantes portugueses e de encomendeiros espanhóis: "Nós não fomos conquistados por espanhol algum, pois nos fizemos vassalos de nosso rei exclusivamente pelos motivos e palavras dos padres" (RABUSKE, 1978, p. 71). Nesse excerto, os guarani-missioneiros deixam claro que não foram conquistados e optaram por se tornarem vassalos.

Destacando os processos de negociação com a coroa, os indígenas colocam em evidência os seus feitos em prol da Espanha:

Sempre que necessário fomos a Buenos Aires para levantarmos o forte. Também fomos a Montevidéu, para erguer fortaleza [...]. Depois disso fomos ainda ao Paraguai, pacificando os Paraguaios e tornando-os vassalos fiéis como nós mesmos. Vês dessa forma o que fizemos por nosso santo Rei, perdendo nossa fazenda e vida, e o que fizemos pelo nosso Deus. (RABUSKE, 1978, p. 71).

Em outras cartas, os guarani-missioneiros deixam claro que possuíam direitos sobre aquelas terras e que não sairiam delas:

Considera o que nosso santo rei da Espanha te falou, quando te enviou, pois te disse que amasses a todos os filhos da igreja, e agora és o seu inimigo mortal. Portanto, desta terra em que estamos, não sairemos enquanto não nos acharmos reduzidos a cinzas, e muito menos de nossas fazendas. (RABUSKE, 1978, p. 76).

Esse excerto é bem característico da resistência dos Guarani, que, na impossibilidade de ficarem em suas terras, optavam pela guerra:

Sendo assim, não teremos medo do mal que nos queres fazer e, ainda que tragas teus canhões não haveremos de recear [...].

Por isso teremos guerra, se vierdes, esta queremo-la nós, caso venhas, e então nos animaremos e haveremos de marchar contra ti, até que te vençamos. É só isto que podes saber [...] Não existe, porém, entre nós quem te haja de temer [...]. (RABUSKE, 1978, p. 78).

Uma preocupação que pairava sobre os guarani-missioneiros é de que abandonarem suas terras levasse a perdas profundas no seu modo de vida. Nesse 
sentido, tem-se a questão da propriedade e da economia nas reduções, pois os guarani-missioneiros não se adequavam ao sistema colonial mercantilista. Assim, os guarani, através do espaço reducional, ainda conservavam relativa autonomia na manutenção de suas práticas produtivo-econômicas tradicionais (LANGER, 2005).

Nesse contexto, o modelo econômico implantado nas missões não é pura e simplesmente a extensão do modelo mercantilista colonial, pois deparou-se com uma sociedade guarani tribal baseada na caça, na pesca e na produção comunitária. Daí decorrem muitas adaptações ao modelo econômico colonial: o Abambaé, que era a propriedade privada de cada família, e o Tupambaé, que era a propriedade coletiva do espaço reducional (KERN, 1982). Contudo os guarani-missioneiros não se adaptavam ao modelo de propriedade privada, optando sempre por seu modus vivendi tradicional de comunitarismo. Os jesuítas sofreram acusações por não inserirem os guarani nesse modelo, porém o que se processava era uma resistência da cultura dos guarani tribal em aderir ao modelo colonial.

Essa resistência ao modelo mercantilista colonial é consciente, pois, quando submetido àquele modelo, sucumbiu a escravidão, por exemplo. Portanto os guarani-missioneiros conheciam o modelo, ao qual optaram por se opor. Daí decorre outra análise: a de que os guarani-missioneiros percebiam que abandonar as terras implicaria o comprometimento da unidade étnica constituída nas reduções. Essa constatação se fundamenta na religiosidade guarani, que observa na terra um elemento fundamental, pois é a terra a responsável pela coesão da vida sociopolítica e econômica (LANGER, 2005).

Desse modo, as cartas dos guarani-missioneiros indicam que seus valores e práticas religiosas, econômicas, sociais e políticas corriam o risco de serem alienadas e, por isso, escolhem a luta, mesmo diante da ameaça de serem reduzidos a cinzas:

É que, olhando para nossos quatro ervais, os quatro grandes algodoais e nossa estância, não temos para onde mudar-nos. Não encontramos nenhuma terra boa para fazer igreja, para fundar o povoado, nem para um bom erval, nem ainda para uma boa estância. E assim nos resta apenas sofrermos e termos extrema pobreza e trabalho. (RABUSKE, 1978, p. 76).

Assim sendo, "A terra missioneira, além de aparecer como o espaço em que se desenvolve a vida material, constitui, simultaneamente, um símbolo de unidade étnica" (LANGER, 2005, p. 93). 


\section{NA COLONIALIDADE DE GÊNERO AS FRONTEIRAS DAS DIFERENÇAS}

Conforme mostra a produção historiográfica dos últimos anos, notadamente os estudos de López de Mariscal (1997), Fleck (2006), Martins (2000) e Mendes (2013), as indígenas da etnia guarani foram representadas, ora como mancebas auxiliares do demônio e provocadoras da lascívia e da luxúria, ora como mulheres devotas e congregantes.

Como bem destacaram Mendes (2013) e López de Mariscal (1997), nas narrativas institucionais masculinas, eivadas por estereótipos e por regras próprias de composição, as mulheres guarani das reduções foram narradas nas primeiras cartas, e silenciadas nas últimas. Também essas mulheres não foram razões centrais das cartas. Nas Cartas Ânuas, segundo Mendes,

[...] nos primeiros 40 anos, as mulheres indígenas aparecem com frequência nos relatos dos missionários, envolvidos no torvelinho da ação evangelizadora. Porém, a partir da segunda metade do século XVII, tornam-se menos assíduas nas narrativas, devido à preponderância dos casos edificantes de conversão que são perpassados pelas representações de gênero ocidentais. No século seguinte (1700-1750), as mulheres indígenas desaparecem gradualmente dos relatos, ficando suas referências limitadas às descrições dos missionários, como Pedro Lozano, Antonio Sepp e José Sanchéz Labrador, entre outros. (MENDES, 2013, p. 50).

Mediante olhares teóricos diversos, é possível pensar sobre as mulheres guarani nas reduções jesuíticas. Aqui, sob o aporte dos estudos decoloniais e feministas, indagamos sobre colonialidade de gênero e as fronteiras das diferenças no projeto colonizador jesuítico nas reduções implantadas na Província do Paraguai, nos anos mil e seiscentos e mil e setecentos.

Para María Lugones (2014, p. 28, tradução nossa), "a colonização foi um processo dual de inferiorização racial e subordinação de gênero" Nesse processo, as mulheres indígenas foram classificadas em dupla inferioridade dos estereótipos ocidentais cristãos sobre o feminino e o sujeito não ocidental. Em grande medida, as representações dos colonizadores naturalizavam as mulheres indígenas como selvagens, irracionais e lascivas.

No afã das tentativas missionais de eliminar a poligamia nas reduções para implantar o casamento monogâmico e a moral da castidade, as mulheres guarani 
foram incorporadas, não sem resistência, conforme enfatizam os estudos acima mencionados, ao que Lugones (2014) nomeou como colonialidade de gênero.

Segundo o pensamento decolonial de Lugones (2014), na colonialidade do poder as categorias existem para legitimar as relações de dominação do sistema colonial, e para excluir as mulheres da chamada espera pública colonial.

A construção de hierarquias entre humanos e não humanos, entre mulheres e homens, a partir de uma matriz de poder global objetivou criar nas missões pelos códigos ocidentais o humano e o gênero. Sob a concepção de gênero imposta pelos jesuítas, sujeitos em situação colonial das reduções foram normatizados mulheres e homens, humanos e não humanos. Assim, para Lugones (2014, p. 938), “A 'missão civilizatória' colonial era a máscara eufemística do acesso brutal aos corpos das pessoas através de uma exploração inimaginável, violação sexual, controle da reprodução e terror sistemático".

Os padres provinciais por meio da pregação sobre o casamento monogâmico, a castidade e a devoção religiosa tentaram impor às mulheres guarani sua concepção estereotipada do lugar da mulher nas reduções, mantendo-as longe de seus olhos, de seus corpos e, principalmente, da relevância delas na organização social guarani, conforme mostram Fleck (2006) e Martins (2000).

As mulheres anciãs resistentes às imposições missionais foram representadas nas primeiras cartas ânuas como verdadeiras brujas: "São as velhas, tenazes nos costumes antigos, as que transformam a cabeça dos demais, sendo elas umas verdadeiras bruxas." (DÉCIMA CARTA ÂNUA DE 1635-1637 apud FLECK, 2006, p. 625, tradução da autora).

Porém, anos depois, mulheres guarani foram nomeadas devotas fervorosas, pregadoras e apóstolas, assim classificadas pelos padres provinciais a partir dos atos delas que eles julgavam como defesa da pureza e adesão aos valores inacianos.

Mesmo os atos das mulheres compreendidos pelos padres como de aceitação do modo de vida cristão foram valorados segundo ótica patriarcal: "resistem varonilmente as mulheres a qualquer provocação" (CARTA ÂNUA DE 1641-1642 apud FLECK, 2006, p. 630). A resistência foi vista como um valor masculino, uma demonstração da força dos homens, não das mulheres.

Ante a capilaridade da colonialidade do poder, nos primeiros anos das reduções jesuíticas-guarani, segundo mostram Mendes (2013) e Martins (2000), a resis- 
tência dos (as) guarani quanto a imposição do casamento monogâmico deu-se por diversos modos, desde a fuga das reduções a mortificações, passando por continuação das práticas. Quanto à resistência, Fleck (2006, p. 621) afirma que "Negando-se a receber o batismo e a admitir o casamento cristão, muitos fugiram das reduções ou adotaram a estratégia de esconder suas concubinas e filhos, enquanto viviam nas reduções, aparentemente, de acordo com as normas morais cristãs".

Embora seja possível perceber, nas narrativas epistolares dos padres, a resistência das mulheres ao projeto colonial-cristão, especialmente o enfrentamento de algumas mulheres guarani às normas impostas à sexualidade, o único papel social disponível às mulheres guarani estava intrínseco à subordinação do feminino aos valores cristão, ou seja, a Deus, aos padres, ao pai ou ao marido, nessa ordem patriarcal. Sendo assim, é possível afirmar na esteira do pensamento de Lugones (2014, p. 28, tradução nossa) que "a transformação do poder do estado em poder masculino se deu excluindo as mulheres das estruturas estatais." A subordinação das mulheres guarani nas reduções jesuíticas-guaranis foi um modo de excluí-las da estrutura estatal.

Viúvas e órfãs foram enviadas à Cotiguaçu, uma habitação nas reduções para as mulheres sem família, sem a tutela do pai ou do marido. Os padres exerceram a tutela patriarcal afastando essas mulheres do modo de vida guarani. Segundo Mendes (2013, p. 58), o Cotiguaçu atendeu ao controle da circulação das muIheres, que ficaram sem pais ou maridos em função das guerras, das doenças e das migrações. Para esse espaço, também foram enviadas as mulheres de outros grupos étnicos aprisionadas nas guerras. Essas práticas de enclausuramento foram consolidadas entre o final do século XVII e o começo do XVIII. Mas o que as mulheres fizeram desse espaço é uma problemática a ser refletida historicamente. Cabe perguntar sobre as (re)criações das mulheres no Cotiguaçu, sobre os modos de resistências à colonialidade dentro de um espaço imposto pela colonialidade de gênero, e sobre a habitação como materialização da colonialidade de gênero, na medida em que, nesse espaço, possam ter estabelecido distinções hierárquicas entre as mulheres em função da etnia, do modo como foram enclausuradas e das relações de gênero estabelecidas no Cotiguaçu.

Os padres provinciais, sob alegação de afastar o pecado, expandiram suas ações sobre a sexualidade dos povos guaranis. Para eles, as mulheres eram pe- 
rigosas por incitá-los à quebra do voto de castidade; a associação da mulher ao pecado era recorrente nos escritos dos religiosos das missões jesuíticas-guarani (MENDES, 2013). Além das medidas práticas como tentar retirar as mulheres guarani da circulação nas reduções, os religiosos, em suas narrativas, demonizaram ou santificaram as mulheres, de modo a afastá-las da mulher que eram e a impor a concepção e o padrão de gênero feminino ocidental.

Contudo, se pensarmos inspirados(as) em Glórias Anzaldua, importante intelectual do pensamento decolonial desde as questões de gênero e etnicidade, o estabelecimento do modo de viver ocidental cristão nas reduções, frente aos modos de viver dos povos ali reduzidos, possibilitou que "As fronteiras se estabelecem para definir os lugares que são seguros e inseguros, para distinguirmos nós e eles" (ANZALDUA, 2012, p. 61, tradução nossa). Os sujeitos que vivem nessas fronteiras são tidos como transgressores por estabelecer e evidenciar em seus corpos e modo de viver as diferenças que o projeto colonial objetivou eliminar. Desse modo, é possível pensar o cotiguaçu como fronteira tanto das hierarquias de gênero e de raça do projeto missional quanto do modos de vidas das mulheres, como um espaço de (re)existência na qual mulheres inscreveram a diferença como resistência.

Se pensarmos a prática do enclausuramento e de normatização do comportamento das mulheres como práticas da colonialidade de gênero, podemos perguntar em que medida os atos de resistência e de aceitação foram meios para o estabelecimento das fronteiras dentro do projeto reducional jesuítico e, especialmente, para o surgimento das "fronteiriças como transgressoras alienígenas, estrangeiras" (ANZALDUA, 2012, p. 61, tradução nossa), mulheres que foram a diferença tanto no projeto colonizador quando no modo de viver guarani até então.

Dentro do processo dual de colonização implantado nas missões jesuíticas as mulheres guarani foram as bordelands que com seus atos re-existiram a despeito da subordinação, da inferiorização e da exclusão em curso sobre suas vidas. Diante da distinção hierárquica entre bruxas velhas e virgens devotas, mulheres guarani em situação colonial nas reduções foram transgressoras, fissuraram os limites impostos, expuseram as fronteiras da colonialidade de gênero do projeto missional jesuítico na América. 


\section{A LUTA INDÍGENA COMO NEGAÇÃO DE OPRESSÃO: AUTODETERMINAÇÃO E DESCOLONIALIDADE}

A noção de autodeterminação costuma gerar alguns imbróglios. A primeira observação que se pode fazer é de que a ideia de autodeterminação não era consciente nos guarani dos Sete Povos, mas que a categoria de análise pode ajudar a compreender a resistência indígena. Como? A resistência guarani-missioneira demonstra, principalmente através das cartas aqui apresentadas brevemente, que eles reconheciam seus direitos sobre o território missioneiro e, de igual modo, reconheciam que perder as terras implicaria o comprometimento das práticas enquanto grupo étnico. Nesse sentido, como já exposto, os guarani reconheciam diferenças sociais, econômicas e políticas em relação aos outros atores daquela ordem. Diante disso, percebe-se que o reconhecimento de direitos, de diferenças e, por conseguinte, de resistência em forma de luta caracterizam a autodeterminação de sujeitos subalternizados.

Nesse sentido, questiona-se por que, ao invés de autodeterminação, não se adota um termo mais efetivo, como o de liberdade dos indígenas. A esse questionamento cabe responder que a autodeterminação é pré-condição para alcançar liberdade. Além disso, entende-se ser mais complicado pensar em liberdade do que em autodeterminação no contexto de colonialismo intenso.

Assim sendo, a ideia de autodeterminação, aqui apresentada, refere-se ao reconhecimento de direitos e de diferença. Obviamente não se trata de um dispositivo legal que atuaria em prol dos guarani, pois esse conceito não fazia parte daquela época, mas sim como uma categoria capaz de ser observada já naquele contexto da resistência guarani. Ou seja, o reconhecimento de diferença e dos direitos que dispunham os guarani caracteriza a resistência guarani-missioneira como um processo de autodeterminação de sujeitos subalternizados (e de descolonialidade).

A concepção de que os guarani-missioneiros reconheciam diferenças em relação aos atores que compunham aquela ordem permite, igualmente, observar o processo de resistência como um processo que marca questões de descolonialidade. A descolonialidade refere-se à superação das colonialidades do ser, do poder e do saber. A descolonialidade dialoga diretamente com a concepção de autodeterminação, pois ambas se referem à questão da diferença e da alteridade, bem como à busca por direitos e autonomia (SANTOS, 2017). 
Portanto o reconhecimento pelos guarani-missioneiros de seus direitos e, por conseguinte, a luta por esses direitos, bem como o reconhecimento de diferenças e de incompatibilidade com o modelo colonial são marcas que me permitem pensar a descolonialidade, mesmo no seio do colonialismo, pois a descolonialidade não está ligada necessariamente à liberdade, mas sim a pensamentos e atitudes.

Quando obrigados a saírem das terras pelo acordado no tratado de 1750, argumentavam os guarani-missioneiros de São João do Uruguai que o Rei, voz de Deus na terra, havia dado aquela terra a eles e, desta feita, Deus não mudaria de ideia. Na mesma carta diziam: "Além disso, estamos lembrados de que eles [portugueses] lutaram contra nossos antepassados, matando a muitos deles, e depois de tudo isso querem tirar-nos e afastar-nos de nossa terra a nós, que somos os seus filhos" (RABUSKE, 1978, p. 72, grifo nosso). Na mesma carta, os índios diziam que, tendo em vista a troca de territórios entre Espanha e Portugal, o rei "[...] não sabe quem são os portugueses e qual é o ser (valor) de nossa terra!" (RABUSKE, 1978, p. 72, grifo nosso).

Na carta do povo de Santo Ângelo, os índios argumentavam que o rei lhes dera respaldo e que tinham direitos de permanecer naquela terra, de modo que questionam o fato da transmigração, apontando que Deus não os ama menos que aos espanhóis e que, por isso, Deus culparia e castigaria "Àquele que quis expulsá-los de suas terras" (RABUSKE, 1978, p. 77, grifo nosso).

Nessas passagens fica evidente a noção dos indígenas de que aquelas terras Ihes pertenciam e, por conseguinte, tinham direitos sobre elas. Em termos mais claros, as posições do líder Sepé Tiaraju são ainda mais enfáticas no que se refere ao reconhecimento de direitos pelo território:

[...] dizem-nos que devemos abandonar as nossas terras, as nossas culturas, nossas casas e até a nossa pátria. Isso não é uma ordem de Deus, mas do Demônio. [...] É muito fácil dizer: - Vocês, índios, dêem suas terras e tudo o que têm aos portugueses. - Mas nunca acreditamos nisso e nunca tal acontecerá. Por que o nosso rei não dá aos portugueses Buenos Aires, Santa Fé, Corrientes e o Paraguai? (CARTA DE SEPÉ TIARAJU, in LUGON, 1976, p. 290).

Essa forte oposição dos guarani-missioneiros ao tratado é entendida por Langer (2005) como traços importantes da identidade e de valores dos guarani- 
-missioneiros que se opuseram ao translado das terras. O autor entende que o conflito ganhou incrementos, pois os guarani-missioneiros tinham consciência da autossuficiência econômica e das diferenças de seu sistema econômico em relação aos coloniais, e da soberania que exerciam sobre o território reducional e que, por isso, os interesses do mundo colonial, em termos econômicos e organizacionais, não eram compatíveis com os seus.

Em suma, reconhecendo a diferença, os guarani-missioneiros optam por modelos, pensamentos e formas organizacionais próprias, descolados do colonizador, do opressor, gerando uma situação de distanciamento entre o modelo reducional e o sistema colonial, marcada, também, pela soberania dos guarani-missioneiros sobre o espaço reducional; esses são elementos centrais para se pensar a descolonalidade.

Na carta do povo de La Concepcion, fica evidente a noção de agir por si mesmos dos indígenas, descolados do elemento colonizador (Portugal e Espanha):

Os portugueses e, nem ainda, qualquer espanhol, nos deram qualquer coisa. A magnífica igreja, a estância dos nossos animais, o erval, o algodoal, a chácara e o que para ela se faz preciso: tudo isso vem a ser enorme trabalho, feito exclusivamente por nós mesmos. (RABUSKE, 1978, p. 93).

As cartas demonstram a emancipação tutelar dos indígenas, mesmo que durante seus escritos eles se coloquem como filhos dos padres e do rei. De igual modo, refletem que os guarani tinham consciência de que tudo o que construíram era fruto unicamente de seu esforço e que, por isso, não concebiam a mudança de suas terras.

\section{CONSIDERAÇÕES FINAIS: DO ENCOBRIMENTO AO PROTAGONISMO DOS(AS) ÍNDIOS(AS) DAS MISSÕES}

As missões jesuíticas da Província Jesuítica do Paraguai configuram-se como um dos temas mais complexos, controversos, intrigantes e instigantes da história colonial. A experiência de jesuítas e índios continua sendo objeto de novas problematizações e hipóteses no meio acadêmico.

Muitos estudos construíram uma narrativa apaixonada sobre a questão, lançando hipóteses de que as missões foram um projeto político utópico guiado de 
maneira brilhante pelos jesuítas. Esses trabalhos supervalorizaram o trabalho dos padres, mas não se atentaram para o cerne da questão: os contatos interétnicos e, por conseguinte, seus efeitos sobre o cotidiano missioneiro.

A conjuntura atual de luta intensa das comunidades indígenas pelo direito à terra, pede que se lancem novas interpretações para o passado, a fim de que esse contexto de luta seja inserido em um processo de longa duração. Desse modo, a análise do passado histórico missioneiro deve estar mais atenta ao protagonismo indígena daquele período do que aos espetaculares feitos dos jesuítas, elucidando a importância de outros atores.

As críticas feministas decolonais suscitam miradas à documentação e à historiografia sobre as missões de modo a colocar em evidência a colonialidade de gênero do projeto missioneiro e as resistências a esse projeto. Em tempo, os estudos feministas decoloniais estimulam refletir sobre as razões da dicotomização e da hierarquização das mulheres e dos homens dos povos indígenas, assim como criticar os modos de operação do saber para eliminar os sujeitos femininos das narrativas históricas. É urgente contar uma história do protagonismo indígena desde as questões de gênero e etnicidade.

Analisando o protagonismo indígena, a resistência guarani contra o tratado se apresenta como um marco fundamental da luta por direitos fundamentais. A tutela dá lugar à autodeterminação e luta contra um sistema opressor, ainda que os guarani venerassem o rei em seus discursos. A partir da consideração de que os indígenas agiram segundo seus interesses e objetivos, ampliam-se as oportunidades para se entender as estratégias e negociações levadas a cabo pelos índios para conservarem sua unidade étnica em um ambiente de opressão e colonialismo intensos.

\section{REFERÊNCIAS}

ANZALDÚA, Gloria. Borderlands/La frontera: la nueva mestiza. México: PUEG - UNAM, 2012.

BALLESTRIN, Luciana. América Latina e o giro decolonial. Revista Brasileira de Ciência Política, Brasília, n. 11, p. 89-117, ago. 2013.

BARTH, Fredrik. Ethnic groups and boundaries: the social organization of culture difference. Oslo, Noruega: Universitetsforlaget, 1969. 
BERNADI, Mansueto. O primeiro caudilho sul rio-grandense: a fisionomia do herói missioneiro Sepé Tiaraju. Porto Alegre: Globo, 1957.

BRUXEL, Arnaldo. Os Trinta Povos Guaranis. Porto Alegre: Sulina, 1978.

CAVALCANTE, Thiago Leandro Vieira. Etno-história e história indígena: questões sobre conceitos, métodos e relevância da pesquisa. História, Franca, SP, v. 30, n. 1, p. 349-71, jan./jun. 2011. DOI http://dx.doi.org/10.1590/S0101-90742011000100017.

COHN, Clarice. Culturas em transformação: os índios e a civilização. São Paulo em Perspectiva, São Paulo, v. 15, n. 2, p. 36-42, abr./jun. 2001.

FLECK, Eliane Cristina Deckmann. De mancebas auxiliares do demônio a devotas congregantes: mulheres e condutas em transformação (reduções jesuítico-guaranis, séc. XVII). Revista Estudos Feministas, Florianópolis, v. 14, n. 3, p. 617-34, set./dez. 2006.

FLORES, Moacyr. Colonialismo e Missões Jesuíticas. Porto Alegre: Edições EST, 1996. DOI 10.1590/S0104-026X2006000300003. Disponível em: http://www.scielo.br/scielo. php?script=sci_arttext\&pid=S0104-026X2006000300003\&lng=en\&nrm=iso. Acesso em: 23 jul. 2015.

GOLIN, Tau. A Guerra Guaranítica: o levante indígena que desafiou Portugal e Espanha. São Paulo: Terceiro Nome, 2014.

GOLIN, Tau. A Guerra Guaranítica: como os exércitos de Portugal e Espanha destruíram os Sete Povos dos Jesuítas e índios Guaranis no Rio Grande do Sul (1750-1761). Passo Fundo, RS: EDIUPF, 1998.

GOLIN, Tau. Missões jesuíticas do Paraguai: uma sociedade alternativa. Revista IHU, ano X, n. 350, p. 28-30, 8 nov. 2010. Entrevista concedida a Patrícia Fachin. Disponível em: http:// www.ihuonline.unisinos.br/media/pdf/IHUOnlineEdicao350.pdf. Acesso em: out. 2014.

GOULART, Jorge Salis. A formação do Rio Grande do Sul. Porto Alegre: Martins Livreiro, 1978.

JAEGER, Luiz Gonzaga. Os heróis de Caaró e Pirapó. Porto Alegre: Globo, 1940.

KERN, Arno Alvarez. Missões: uma utopia política. Porto Alegre: Mercado Aberto, 1982.

KERN, Arno Alvarez. Problemas teórico-metodológicos relativos à análise do processo histórico missioneiro. In: JORNADA INTERNACIONAL DE ESTUDOS MISSIONEIROS. MONTOYA E AS REDUÇÕES NUM TEMPO DE FRONTEIRAS, 6. Anais [...]. Santa Rosa, RS, 1985.

LANGER, Protásio Paulo. Os Guarani-Missioneiros e o Colonialismo Luso no Brasil meridional: projetos civilizatórios e faces da identidade étnica (1750-1798). Porto Alegre: Martins Livreiro Editor, 2005. 
LÓPEZ DE MARISCAL, Blanca. La figura femenina en los narradores testigos de la conquista. México: El Colegio de México; Consejo para la Cultura de Nuevo Léon, 1997.

LUGON, Clóvis. A república comunista cristã dos guaranis. Rio de Janeiro: Paz e Terra, 1976.

LUGONES, María. Colonialidad y género. Hacia un feminismo descolonial. In: JIMÉNEZLUCENA, Isabel; LUGONES, María; MIGNOLO, Walter; TLOSTANOVA, Madina. Género y descolonialidad. 2. ed. Buenos Aires, Argentina: Ediciones Del Signo, 2015. Disponível em: http://www.Irmcidii.org/wp-content/uploads/2015/05/Genero_y_Descolonialidad. pdf. Acesso em: 4 abr. 2018.

LUGONES, Maria. Rumo a um feminismo descolonial. Revista Estudos Feministas, Florianópolis, v. 22, n. 3, p. 935-52, set./dez. 2014. Disponível em: https://periodicos. ufsc.br/index.php/ref/article/view/36755. Acesso em: 26 jun. 2018.

MARTINS, Maria Cristina Bohn. "Desvergonzadas" ou "Escravos da Virgem": representações femininas nas Cartas Ânuas. In: ENCONTRO DA ANPHLAC, 4., Salvador, BA, 2000. Anais Eletrônicos [...]. Disponível em: http://anphlac.fflch.usp.br/iv-encontro. Acesso em: 16 jun. 2018.

MASO, Tchella Fernandes; SÉLIS, Lara Martins Rodrigues. Práticas inter/indisciplinadas nas relações internacionais: acesso e mediação ao conhecimento subalternizado. In: SEMINÁRIO DE RELAÇÕES INTERNACIONAIS: GRADUAÇÃO E PÓS-GRADUAÇÃO, 2., 2014, João Pessoa, PB. Anais [...]. Disponível em: http://www.seminario2014. abri.org.br/resources/anais/21/1410957070_ARQUIVO_MASO_SELIS_Praticasinter. indisciplinadasnasRI_1.pdf. Acesso em: jan. 2018.

MELIÁ, Bartomeu. El Guarany conquistado y recducido. Assunção, Paraguai: Cepag, 1997.

MELIÁ, Bartomeu. Las reducciones jesuíticas del Paraguay: un espació para una utopia colonial. Estudios Paraguaios, Assunção, Paraguai, v. 6, n. 1, p. 157-67, set. 1978.

MELIÁ, Bartomeu; NAGEL, Liane Maria. Guaranís y jesuítas en tiempo de las misiones. Assunción, Paraguai: Cepag, 1995.

MENDES, Isackson Luiz Cavilha. As mulheres indígenas nos relatos jesuíticos da província do Paraguai (1609-1768). 2013. 131 f. Dissertação (Mestrado em História)- Instituto de Filosofia e Ciências Humanas, Programa de Pós-Graduação em História, Universidade Federal do Rio Grande do Sul (UFRGS), Porto Alegre, 2013.

MIGNOLO, Walter. Histórias locais, projetos globais: colonialidade, saberes subalternos e pensamento liminar. Belo Horizonte: Ed. UFMG, 2003.

MOHANTY, Chandra. Bajo los ojos de Occidente: saber academico y discursos coloniales. In: Estudios postcoloniales: ensayos fundamentales. Madrid, Espanha: Traficantes de Sueños, 
2008. Disponível em: https://www.traficantes.net/sites/default/files/pdfs/Estudios\%20 Postcoloniales-TdS.pdf

MONTOYA, Antonio Ruiz de. Conquista espiritual feita pelos religiosos da Companhia de Jesus nas Províncias do Paraguai, Paraná, Uruguai e Tapé. Tradução: Arnaldo Bruxel. Porto Alegre: Martins Livreiro, 1985.

NEUMANN, Eduardo Santos. Práticas letradas Guarani: produção e usos da escrita indígena (séculos XVII e XVIII). 2005. 381 f. Tese (Doutorado em História)- Universidade Federal do Rio de Janeiro, Rio de Janeiro, 2005.

NEUMANN, Eduardo Santos. O trabalho guarani missioneiro no Rio da Prata Colonial. Porto Alegre: Martins Livreiro, 1996.

OLIVEIRA, Oseias de. Reinterpretação cultural nas missões: a conversão de índios e missionários no Guairá. Jundiaí, SP: Paco Editorial, 2014.

OLIVEIRA, Roberto Cardoso de. Identidade étnica, identificação e manipulação. Sociedade e Cultura, Goiânia, v. 6, n. 2, p. 117-31, jul./dez. 2003.

OLIVEIRA, Roberto Cardoso de. Identidade, etnia e estrutura social. São Paulo: Pioneira, 1976.

PORTO, Aurélio. História das missões orientais do Uruguai. Porto Alegre: Selbach, 1954.

QUEVEDO, Julio. Guerreiros e jesuítas na utopia do Prata. Bauru, SP: EDUSC, 2000.

QUEVEDO, Julio. A guerra guaranítica. São Paulo: Ática, 1996.

QUIJANO, Anibal. Colonialidade do poder, eurocentrismo e América Latina. In: LANDER, Edgardo (Org.). A colonialidade do saber: eurocentrismo e ciências sociais. Perspectivas latino-americanas. Buenos Aires, Argentina: CLACSO, 2005.

RABUSKE, Arthur. Cartas de índios cristão do Paraguai, máxime dos Sete Povos, datadas de 1753. Estudos Leopoldenses, São Leopoldo, RS, v. XIV, n. 47, p. 65-102, 1978.

ROJAS, José Luis de. La etnohistoria de América. Los indígenas protagonistas de su historia. Buenos Aires, Argentina: SB, 2008.

SANTOS, Carolina Mendonça. Terra e autodeterminação: o usofruto indígena na constituição de 1988. 2017. 177 f. Dissertação (Mestrado em Sustentabilidade junto a Povos e Terras Tradicionais) - Universidade de Brasília (UnB), Brasília, 2017.

SOUSA, Octávio Tarquínio. Colecção documentos brasileiros. Rio de Janeiro: Livraria José Olympio, 1939. v. 19. 
SPIVAK, Gayatri C. Pode o subalterno falar? Belo Horizonte: UFMG, 2010.

TESCHAUER, Carlos. História do Rio Grande do Sul dos dois primeiros séculos. Porto Alegre: Selbach, 1921.

TORRES-MALDONADO, Nelson. Sobre la colonialidad del ser: contribuciones al desarrollo de un concepto. In: GOMES-CASTRO, Santiago; GROSFOGUEL, Rámon (Eds.). El giro decolonial: reflexiones para una diversidad epistémica más allá del capitalismo global. Bogotá: Siglo del Hombre Editores, 2007.

VELLINHO, Moysés. Capitania D’El-Rei: aspectos polêmicos da formação Rio-Grandense. Porto Alegre: Globo, 1970.

\section{Sobre os autores:}

Mateus Brunetto Cari: Mestrando do Programa de Pós-Graduação em História da Universidade Federal da Grande Dourados (UFGD). Bacharel em Relações Internacionais pela UFGD. E-mail: mateus.bcari@gmail.com

Paula Faustino Sampaio: Doutora em História pela Universidade Federal da Grande Dourados (UFGD). Mestre em História pela Universidade Federal de Pernambuco (UFPE). Professora da Universidade Federal de Mato Grosso (UFMT), Campus de Rondonópolis. E-mail: paulafaustinosampaio@hotmail.com

Recebido em 2 de julho de 2018

Aprovado para publicação em 23 de outubro de 2018 